\title{
Coupled DEM-CFD investigation of the formation of landslide dams in narrow rivers
}

\author{
Tao Zhao, Feng Dai*, Nu-wen Xu \\ State Key Laboratory of Hydraulics and Mountain River Engineering, College of Water Resource \\ and Hydropower, Sichuan University, 610065, China \\ * Corresponding author: Tel.: +8628 85406701 E-mail: fengdai@ scu.edu.cn
}

\begin{abstract}
Large-scale landslide dams can induce significant hazards to human lives by blocking the river flows and causing inundation upstream. They may trigger severe outburst flooding that may devastate downstream areas once failed. Thus, the advancement in understanding the formation of landslide dams is highly necessary. This paper presents three dimensional numerical investigations of the formation of landslide dams in open fluid channels via the Discrete Element Method (DEM) coupled with Computational Fluid Dynamics (CFD). By employing this model, the influence of flow velocity on granular depositional morphology has been clarified. As the grains settle downwards in the fluid channel, positive excess water pressures are generated at the bottom region, reducing the total forces acting on the granular mass. In the meantime, the particle sedimentations into the fluid channel with high impacting velocities can generate fluid streams to flow backwards and forwards. The coupled hydraulic effects of excess water pressure and fluid flow would entrain the solid grains to move long distances along the channel. For simulations using different flow velocities, the larger the flow velocity is, the further distance the grains can be transported to. In this process, the solid grains move as a series of surges, with decreasing deposit lengths for the successive surges. The granular flux into the fluid channel has very little influence on the depositional pattern of particles, while it affects the particle-fluid interactions significantly. The results obtained from the DEM-CFD coupled simulations can reasonably explain the mechanisms of granular transportation and deposition in the formation of landslide dams in narrow rivers.
\end{abstract}

Keywords landslide dams, DEM-CFD coupling, granular transport, fluid channel, excess water pressure, granular surges 


\section{Introduction}

Landslides occurred near valley rivers with steep bank slopes would potentially create landslide dams, as a large amount of failed slope mass can block the river channels (Fan et al. 2012, Xu et al. 2009, Xu et al. 2013). Due to their rather loose soil structure and absence of controlled flow spillway, landslide dams frequently fail catastrophically, leading to serious downstream inundation and flooding, often with high casualties. A common failure scenario of landslide dams is overflowing with subsequent dam breaching and erosion by the overflow streams (Wu et al. 2014). Some large landslide dams occurred in history are listed here as the gigantic Usoi dam in Tajikistan (Ischuk 2011), the Tortum landslide dam in Turkey (Duman 2009) and the Tangjiasha landslide dam in China (Xu et al. 2009). In these cases, proper mitigating measures, such as the construction of spillways, removal of damming solid mass, were used before dam failure (Yan et al. 2009). In addition, the historic landslide dams can also have long-term influence on the valley morphology and environments. For instance, the deposition of alluvial or sediments in river floor can change the stream gradient, surface morphology and upstream superficial geology (Fan et al. 2012, Micu and Bălteanu 2013).

For many years, myriads of efforts have been devoted to study the characteristics of landslide dams, including site investigations and laboratory experiments (Fan et al. 2012, Xu et al. 2013, Yan et al. 2009, Zhou et al. 2013, Zhou et al. 2013). The purpose is to understand the initiation, propagation and deposition mechanisms of landslides and the subsequent formation of dams (Micu et al. 2014). Once landslides are initiated, the failed solid masses can move downslope and travel distances several times larger than the initial sizes of their source topography. The highly mobilized solid mass would stop moving and pile up when it reaches the bottom valley and plunges into rivers (Huang and Tang 2014). Depending on the solid flux, river flow velocity and river width, the solid mass can block the rivers completely, partially damming or channel diversion (Fan et al. 2012). Fan et al. (2012) analysed the geomorphometric parameters of 828 landslide dams triggered by 2008 Ms 8.0 Wenchuan earthquake, China. They found out that the river width and landslide dam volume are linearly related. Power-law relations are hold between landslide areas and dam widths, landslide source areas and dammed areas, as well as lake areas and lake volumes. In this process, the mechanism of granular transportation and deposition in fluid determines the possibility of dam formation in rivers. In addition, the impounded water in landslide lakes may submerge the upstream area and subsequently induce secondary landslides into the lake (Xu et al. 2009). 
From a microscopic perspective of view, the granular transportation and deposition in fluid involve very complex fluid-solid and solid-solid interactions (Shan and Zhao 2014, Zhao et al. 2014). Numerical simulations of these processes are based on the idea that the motion of particles is completely governed by the Newtonian equations of motion, in which the interparticle collisions can be evaluated by well-defined contact models, while the fluid flow is solved by the Navier-Stokes equations (Chen et al. 2011, Zhao and Shan 2013). To this end, the Discrete Element Method (DEM) (Cundall and Strack 1979) and Computational Fluid Dynamics (CFD) (Anderson 1995) techniques can be used to study the mechanical and hydraulic behaviour of particles and fluid flow, respectively. Indeed, the coupled DEM-CFD method have been widely used to study the intricate continuum-discrete problems, with a variety of engineering and industry applications (Zhu et al. 2008), such as the modelling of submerged granular flows (Topin et al. 2012), granular impacting on a water reservoir (Shan and Zhao 2014), fluidization (Kafui et al. 2002), pneumatic conveying and pipeline flow (Li et al. 2005), blast furnace (Xu et al. 2000), cyclones (Wang et al. 2006) and particle coating process (Nakamura et al. 2006).

Due to the high risks of sudden failure of landslide dams, it is important to understand how these dams form, in particular to clarify the characteristics of granular transportation in fluids and depositional morphology of sediments during the formation of landslide dams. In this regard, the current research has focused on the dynamics of solid grains driven by open channel flows via a coupled DEM-CFD method, aiming to provide new insights into the relationship between the flow velocities and granular depositional morphologies. This paper is organised as follows: in Section 2, the numerical model configuration is illustrated. In Section 3 , the numerical results obtained from the simulations are presented, including detailed discussions of granular deposition morphology, the influence of fluid velocity on the granular motions, and particle-fluid interactions. Conclusions on the capability of the DEM-CFD modelling of granular transportation and deposition are summarized in Section 4. 


\section{Model configurations}

\section{$2.1 \quad$ DEM-CFD coupling model}

The DEM and CFD open source codes ESyS-Particle (Abe et al. 2004, Utili et al. 2015) and OpenFOAM (OpenCFD 2014) were employed for the simulations presented herein. The DEM-CFD coupling algorithm is based on the model proposed by Zhao et al. (2014). In the current analyses, the linear-spring and rolling resistance contact model are used in the DEM to calculate the interaction forces between solid particles. The governing equations of particle motions are expressed as below:

$$
\begin{gathered}
m_{i} \frac{d^{2}}{d t^{2}} \overrightarrow{x_{i}}=m_{i} \vec{g}+\overrightarrow{F_{c}}+\overrightarrow{f_{\text {fluid }}} \\
I_{i} \frac{d}{d t} \overrightarrow{\omega_{i}}=\sum_{c} \overrightarrow{r_{c}} \times \overrightarrow{F_{c}}+\overrightarrow{M_{r}}
\end{gathered}
$$

where $m_{i}$ is the mass of a single particle $i ; \vec{x}_{i}$ is the position of its centroid; $\vec{g}$ is the gravitational acceleration; $\vec{F}_{c}$ is the contact force exerted by the neighbouring particles, which is calculated using a linear-spring model (Cundall and Strack 1979); $\overrightarrow{f_{\text {fuid }}}$ is the force exerted by fluid flow on the particle; $I_{i}=2 m_{i} r^{2} / 5$ is the moment of inertia about the grain geometric centroid, with $r$ being the particle radius; $\overrightarrow{\omega_{i}}$ is the angular velocity; $\vec{r}_{c}$ is the vector from the particle mass centre to the contact point and $\overrightarrow{M_{r}}$ is the rolling resistant moment. In the current analyses, the rolling parameters are chosen the same as those calibrated in Utili et al. (2015).

The governing equations of fluid flow are shown as below:

$$
\begin{gathered}
\frac{\partial\left(\rho_{f} n\right)}{\partial t}+\nabla \cdot\left(\rho_{f} n \mathbf{U}\right)=0 \\
\frac{\partial\left(\rho_{f} n \mathbf{U}\right)}{\partial t}+\nabla \cdot\left(\rho_{f} n \mathbf{U U}\right)-n \nabla \cdot \tau=-n \nabla p+n \rho_{f} \vec{g}+\overline{f_{d}}
\end{gathered}
$$


where $f_{d}=\sum_{i=1}^{N} F_{d i} / V_{\text {mesh }}$ is the drag force per unit fluid volume, with $V_{\text {mesh }}$ being the volume of a fluid mesh cell and $N$ being the number of particles within the cell; $\boldsymbol{\tau}$ is the fluid stress tensor, calculated by the standard $k-\varepsilon$ turbulent model (Launder and Spalding 1972, Wilcox 2006).

The interaction forces between fluid and solid phases are the buoyant $\left(\overrightarrow{f_{b}^{i}}\right)$ and hydrodynamic forces. The buoyant force is related to the particle volume and pressure gradient, calculated as follows:

$$
\overrightarrow{f_{b}^{i}}=-v_{p i} \nabla p
$$

where $v_{p i}$ is the volume of particle $i ; p$ is the pressure of fluid flow.

The hydrodynamic force considered in this study is the fluid viscous drag force, induced by the relative motion between particle and fluid (Kafui et al. 2002). It is calculated by the Di Felice (1994) empirical correlation as:

$$
F_{d i}=\frac{1}{2} C_{d} \rho_{f} \frac{\pi d_{p}^{2}}{4}|\boldsymbol{U}-\boldsymbol{V}|(\boldsymbol{U}-\boldsymbol{V}) n^{-\chi+1}
$$

where $C_{d}=\frac{24}{\operatorname{Re}}\left(1+0.150 \mathrm{Re}^{0.681}\right)+\frac{0.407}{1+8710 / \operatorname{Re}}$ is the drag force coefficient (Brown and Lawler 2003); $\rho_{f}$ and $U$ are the fluid density and velocity; $d_{p}$ and $V$ are the diameter and velocity of a particle, respectively; $\chi=3.7-0.65 \exp \left[-\frac{\left(1.5-\log _{10} \operatorname{Re}\right)^{2}}{2}\right]$, with $\operatorname{Re}=\rho_{f} d_{p} n|\boldsymbol{U}-\boldsymbol{V}| / \mu$ being the Reynolds number defined at the particle size scale, $n$ being the fluid volume fraction in the CFD mesh cells, $\mu$ being the fluid viscosity. In the current analyses, $\chi$ ranges from 3.4 to 3.7 .

\subsection{Granular transport model}

A schematic view of the slope mass sliding into a river is shown in Figure 1. It can be observed that the slope mass normally impact the river at a velocity $V$ and an angle $\theta$ relative to the vertical direction. In addition, the river flows at a velocity $U$ with its direction 
perpendicular to $V$. In the simulations, the initial particle velocities are determined based on statistics of the average granular velocity from a number of landslide site investigations, where a large amount of solid materials fall into rivers and block partially or completely the flow channels. According to the site investigations of the $M s \quad 8.0$ earthquake-induced Tangjiashan landslide dam by Xu et al. (2009) and Fan et al. (2012), the estimated average landslide velocity is $10 \mathrm{~m} / \mathrm{s}$, and the angle $\theta$ is about $60^{\circ}$. As expected, the velocity components along the slope sliding direction $\left(v_{y}\right)$ and the vertical direction $\left(v_{z}\right)$ is very large, while the velocity component perpendicular to the slope sliding direction $\left(v_{x}\right)$ can be neglected. As for the fluid flow, Fan et al. (2012) pointed out that before the landslide, the average annual discharge of the dammed river is $81 \mathrm{~m}^{3} / \mathrm{s}$, and it was recorded as $90 \mathrm{~m}^{3} / \mathrm{s}$ just before the dam breached (Liu et al. 2009). As the cross sectional area of the river channel varies at different locations, the flow velocity $(U)$ is set as a variable ranging from $0 \mathrm{~m} / \mathrm{s}$ to $10 \mathrm{~m} / \mathrm{s}$ in the numerical simulations.

The model configuration of the granular transport is shown in Figure 2, which consists of the solid (DEM component) and the fluid (CFD component) phases. Due to the extremely high computational costs in 3D DEM-CFD modelling of real landslides, the current numerical investigations used periodic boundaries along the y-axis direction, so that the plane strain conditions can be imposed (Zhao et al. 2015). By employing this model, solid/fluid materials going out of one side of the boundary will appear on the opposite side of the model with the same velocities. The solid/fluid materials near one boundary can interact with materials located near boundary at the opposite side of the model. To consider the non-spherical particle shape and interlocking between particles (Belheine et al. 2009, Jiang et al. 2005), the rolling resistance model has been used in the DEM model. Due to the scarcity of field and experimental data for detailed granular motions during the formation of landslide dams, the current study presents mainly numerical results, with the purpose to clarify the general features of granular transportation and deposition in fluid channels.

The parameters used in the DEM-CFD model are listed in Table 1. The values of these input parameters have been calibrated by Utili et al. (2015) and Zhao et al. (2014). Among these parameters, the particle size distribution (PSD) is one of the most important factors controlling the characteristics of landslide dams, such as the dam stability, the strength and permeability of the dam materials (Casagli et al. 2003). As stated by Casagli et al. (2003) and Crosta et al. (2007), the PSD of landslide dam materials varies widely at different sites and 
different depths of a specific dam. The current study attempted to simulate the PSD of solid materials at the bottom layer of the Tangjiashan landslide dam (Chang and Zhang 2010). Due to the computational limitations, the DEM model only employs a much narrower PSD than the real PSD, with approximately the same PSD for grains with percentiles larger than $30 \%$, as shown in Figure 3.

During the simulation, the DEM and CFD modules work as follows:

\section{1) The DEM module}

(1) Grain container: a DEM engine (coded as a C++ class) can continuously generate polydispersed particles within a rectangular prism. Particles are coloured red, pink, yellow, blue and cyan as their diameters decrease gradually. The grain container has a size of $5 \mathrm{~m} \times 5 \mathrm{~m} \times 1 \mathrm{~m}$, and it is placed 2 meters above the fluid channel. In the current study, the granular flux $\left(Q_{p}\right)$ is defined as the number of particles generated per second. Based on the size of the grain container and the range of particle radius, the granular flux $\left(Q_{p}\right)$ can be approximately determined, such that no particle overlapping exists at generation.

(2) Considering the variation of granular velocities during landsliding, $v_{z}$ is set as a variable ranging from $8 \mathrm{~m} / \mathrm{s}$ to $12 \mathrm{~m} / \mathrm{s}$, and $v_{y}$ ranges from 0 to $5 \mathrm{~m} / \mathrm{s}$, while $v_{x}$ is set as zero in the current analyses. As the periodic boundaries are employed along the $y$-axis direction, particles moving across one side of the DEM domain are re-mapped back into the model on the opposite side with the same velocities. As a consequence, all the particles can drop into the fluid channel. By using these parameters, the rock/soil falling into the river channel with initial motion can be simulated. In addition, this approach can also speed up the simulation, as grains can drop into the open fluid channel quickly.

(3) A layer of polydispersed coarse grains are paved on the bottom of the fluid channel to simulate the coarse bottom floor. The PSD of these particles paved on the bottom floor are the same as that of particles generated within the grain container.

\section{2) The CFD module:}

(1) An open fluid channel has been placed horizontally. The dimension of the fluid channel is set as: $a=5 \mathrm{~m}, b=100 \mathrm{~m}, H=10 \mathrm{~m}$. The upper boundary has an open air condition. The left and right boundaries are periodic, and the bottom floor has non-slip boundary conditions (see Figure 4). The back and front boundaries are set as the inlet and outlet of the flow channel. 
(2) A constant fluid flux (Q) is maintained throughout the simulation by setting the fluid velocity at the inlet boundary as a constant value. As the cross section of real rivers varies at different locations, the fluid velocity also varies accordingly. Thus, parametric study of the flow velocity will be analysed in this research.

For the fluid flow, the standard $k-\varepsilon$ model (Launder and Spalding 1972, Wilcox 2006) has been used in the simulations. In this model, the fluid flow velocity near the non-slip boundary wall is shown in Figure 4, which consists of three distinct flow layers. The very thin layer next to the wall is the viscous layer, where the velocity profile is linear and the flow can be treated as laminar. The viscous effect of fluid is significant in this layer and the turbulence can be neglected. Next to the viscous layer is the buffer layer in which both viscous and turbulent effects are significant. Above the buffer layer is the turbulent layer where fully turbulent flow is developed.

\section{Results}

First of all, two types of simulations, namely the single particle transportation and sedimentation, are used to validate the DEM-CFD coupling model. Then, the granular depositions with continuous feeding from the grain container are reported, regarding the deposit height, length, the angle of repose, and particle-fluid interactions. In the analyses, comparisons have been made between results obtained from simulations using the DEM rolling resistance model and the DEM-CFD coupled simulations.

\subsection{Validation of the DEM-CFD model}

To validate the DEM-CFD coupling model, the single particle transportation and sedimentation in fluid have been simulated. For the first case, an artificial "buoyant particle" (i.e. the particle density is set the same as the fluid) is placed in a fluid current. Due to the viscous drag force exerted by fluid flow on the particle, the solid particle would accelerate to move with the same velocity as the fluid flow. The input parameters used in this simulation are listed in Table 2.

As illustrated in Figure 5, the solid particle initially accelerates very fast within a short time interval as it is dragged by the fluid viscous drag forces resulting from the high relative 
velocity between the particle and fluid. Then, the drag force decreases with the relative velocity. As a result, the particle velocity increases slowly until it reaches a velocity very close to the fluid velocity (i.e. $1.0 \mathrm{~m} / \mathrm{s}$ ).

As for the second testing case, the particle sedimentation is simulated using the same model configuration as detailed in Zhao et al. (2014). In the current simulation, the particle radius and density are set as $0.1 \mathrm{~m}$ and $2650 \mathrm{~kg} / \mathrm{m}^{3}$, respectively. The other parameters of the DEM-CFD coupling model are set the same as those listed in Table 1. The motion of a single spherical particle is calculated theoretically as:

$$
\frac{4}{3} \pi r^{3} \rho_{s} \frac{\partial U_{r}}{\partial t}=\frac{4}{3} \pi r^{3}\left(\rho_{s}-\rho_{f}\right) g-\frac{1}{2} \pi r^{2} \rho_{f} C_{d} U_{r}^{2}
$$

where $U_{r}$ is the relative velocity between fluid and particle.

According to Eqn.(7), a forward finite difference numerical technique can be used to calculate the theoretical relative settling velocity at different times, which should be comparable to the numerical results in modelling the grain sedimentations. As shown in Figure 6, a single particle settles under gravity from the static state and accelerates quickly in water. Due to the viscous drag force acting on the grain, the acceleration slows down and the final stable settling velocity is $3 \mathrm{~m} / \mathrm{s}$, which matches the theoretical value very well.

\subsection{Investigation of the granular transportation and deposition}

In this section, the DEM and DEM-CFD coupling models have been used to study the transportation and deposition of granular materials, including the evolution of deposit profile, excess water pressure and flow velocity, deposit length and height, and particle-fluid interactions. The simulations stop once the fluid channel is dammed by the granular piles. From Section 3.2.1 to Section 3.2.3, numerical results of simulations using $U=0 \mathrm{~m} / \mathrm{s}$ and $Q_{p}$ $=640 / \mathrm{s}$ will be given, while results of parametric studies on the fluid velocity $(U)$ and granular flux $\left(Q_{p}\right)$ are given from Section 3.2.4 to Section 3.2.6.

In the DEM-CFD coupled simulations, the excess water pressure $(p)$ is defined as:

$$
p=p_{\text {total }}-p_{0}
$$


where $p_{\text {total }}$ is the total water pressure and $p_{0}$ is the hydrostatic pressure of the fluid flow.

For all the analyses presented herein, the dimensionless time, deposit height and length, velocity, pressure and force are defined as follows:

$$
\begin{gathered}
{[T]=\mathrm{t} / \sqrt{\frac{H}{g}}} \\
{[H]=h / H} \\
{[L]=l / H} \\
{[U]=U / \sqrt{g H}} \\
{[p]=p /\left(\rho_{f} g H\right)} \\
{[F]=F /(m g)}
\end{gathered}
$$

where $t$ is the duration time, $h$ and $l$ are the deposit height and length, respectively; $F$ is the interaction force (e.g. inter-particle contact force, particle-fluid interaction), $m$ is the mass of a particle with the mean diameter of the granular packing (i.e. $D=0.2 \mathrm{~m}$ in this study).

\subsubsection{Evolution of deposit profiles}

The profiles of the deposits vary as the solid grains continuously drop into the channel. The variation also occurs when different numerical models are used in the study (e.g. DEM and DEM-CFD coupled models). In the following figures, the coarse channel floor is represented by a plane of paved grey particles, while the water table is represented by a red straight line. Figure 7 illustrates the sedimentation and deposition of particles in static water. It can be observed that the solid grains move as a sequence of surges. The first surge starts to spread horizontally once the grains reach the bottom channel floor (see the snapshot of $[\mathrm{T}]=2$ ). As can be observed from a series of successive snapshots, solid grains in the first surge move with the highest mobility. This phenomenon can be explained by the fact that the incoming high granular flux into water would generate very high excess water pressure at the channel bottom (see Figure 9), which can effectively reduce the total forces acting on individual 
particles. In addition, the fluid flow induced by the granular sedimentation can also entrain solid grains (especially the fines) in the flow current to move horizontally (see Figure 11). As a result, the granular flow in the first surge is very loose. Due to the high friction and rolling resistance moment acting on grains near the bottom floor, grains in the first surge would gradually deposit on the floor (see the figure of $[T]=10$ ). In the meantime, the incoming granular flux generates the second surge spreading just atop of the first surge. The spreading velocity of the second surge is much slower than that of the first surge (see the figure of $[T]=15$ ), because the excess water pressure below the solid mass has dissipated and the intensive inter-particle interactions restrict the granular motion. After $[\mathrm{T}]=15$, a series of small surges have formed and deposited on the surface of the granular pile. Thus, dense granular flows are dominant for these slowly moving granular surges. The sediments would finally block the river after $[\mathrm{T}]=35$, when a thick and stable granular pile is formed on the river floor. The steepest angle of repose of the granular deposit is around $28^{\circ}$. The surged motion of sediments observed in this study can qualitatively match what has been found in laboratory experiments (Cassar et al. 2005, Gue 2012, Wang and Sassa 2001) well.

As a comparison, results of dry granular sedimentations simulated by the DEM rolling resistance model are presented in Figure 8. In the current simulations, the viscous damping coefficient of the DEM model is set as 0.1 to account for the energy dissipation during the grain collisions. The coefficients of rolling stiffness and plastic moment are set as 1.0 and 0.1 respectively to consider the particle shape effect and granular interlocking. According to Figure 8, dry particles would saltate on the floor as they collide with each other. The bottom grains would gradually cease motion and form a small cone-shaped granular pile. As the simulation continues, the incoming grains continuously fall onto the surface of the pile, sliding/rolling downwards along the inclined surface. Due to inter-particle friction and rolling resistance, the saltating grains would finally deposit on the floor and the surface of granular pile. As a consequence, the volume of the granular assembly increases slowly. During this process, the shape and angle of repose of the granular deposits remain almost unchanged. The granular assembly would reach a height of water table after $[\mathrm{T}]=20$, which is much faster than that observed in Figure 7. The steepest angle of repose of the granular pile is around $30^{\circ}$, which is steeper than that of the granular pile in static water. 


\subsubsection{Excess water pressure and flow velocity}

As mentioned above, the excess water pressure and fluid velocity induced by the granular sedimentation can significantly affect the depositional behaviour of granular mass. Thus, it is necessary to investigate the evolution of these two parameters for detailed understanding of granular dynamics in fluids. In the numerical simulations, as the periodic boundaries have been used in the y-axis direction of the shallow fluid channel, only the averaged fluid velocities and excess water pressures along that direction were analyzed.

Figure 9 illustrates the evolution of excess water pressures within the fluid channel. It can be observed that the positive excess water pressure occurs below the grain container at the bottom region when a large amount of solid grains fall into the channel and generate viscous drag forces on the fluid elements. The value of excess water pressure increases with the simulation time, reaching the peak value at $[\mathrm{T}]=5$. The induced positive excess water pressure can largely reduce the total forces acting on the particles, increasing the mobility of the solid mass. Thus, the particles can travel a long distance along the channel. As more and more particles fall into the channel and form a stable deposit layer on the floor, the excess water pressures within the sediments dissipate gradually. As a consequence, the incoming grains would suffer much higher total forces, resisting their horizontal motions. Finally, a thick sediment layer forms on the bottom floor. The detailed variation of the excess water pressures of the region below the grains generator near the channel floor is shown on Figure 10. As shown in Figure 10, the excess water pressure near the bottom floor increases quickly to the peak value of $[\mathrm{p}]=0.57$ at $[\mathrm{T}]=5$, as the solid grains continuously fall into the channel. During this time period, variations of the recorded values can also be observed, because of the frequent movement of solid flux across this region. Then, the excess water pressure dissipates gradually, with approximately a linear relationship between the excess water pressure and time. After $[\mathrm{T}]=35$, the excess water pressure drops to a negligible value below $[\mathrm{p}]=0.05$.

Figure 11 illustrates the distribution and evolution of fluid flow velocities in the fluid channel. It can be observed that the flow stream is generated once the solid grains drop into the channel. As more and more grains settle downwards, the fluid flows horizontally towards the inlet and outlet regions. The maximum fluid velocities occur near the sediments surface where saltated grains can move quickly with small effective stresses. As a stable deposit layer builds up gradually at the bottom, the fluid velocity within that region decreases to zero. 
When compared with the distribution and evolution of excess water pressure in Figure 9, it can be observed that the maximum fluid velocities occur on both sides of the regions with maximum positive excess water pressures, indicating that the incoming grains can induce high fluid velocities near the deposit surface. In addition, the fluid flow can also transport some particles to both sides of the channel. As a consequence, the coupled effects of excess water pressure and fluid velocity can increase the mobility of grains significantly, resulting in a flat granular deposit on the bottom floor.

\subsubsection{Deposit length and height}

As discussed in Section 3.2.1, the length and height of granular deposits increase gradually, as the incoming grains add to the total solid mass continuously. The analyses of the maximum deposit length and height, and the corresponding time are important for evaluating the potential hazards of landslide dams. Thus, in this section, the evolutions of deposit length and height are discussed in detail. Due to the symmetric geometrical configuration, the deposit length is defined as the backward (for grains moving towards the inlet direction) and the forward (for grains moving towards the outlet direction) lengths of the deposit front to the symmetric axis of the grain container. In addition, as surged motion is dominant for grains moving in water, the deposit lengths of a series surges are presented in the following analyses.

As shown in Figure 12, deposit length of sediment surges increases almost linear with time, until the final constant length is reached. In this process, the sediment surges move successively, such that the second surge starts to move only after the first surge stops moving, while the third surge starts to move just after the second surge stops. From these curves, it can also be observed that for a series of surges, the forward deposit lengths are approximately equal to the backward lengths. In addition, the final deposit lengths decrease gradually for successive surges. This phenomenon can be explained by the fact that particles in the first surge are packed loosely with small resistant forces, and the high excess water pressure decreases the effective stress of the granular packing. Thus, the solid grains can move long distances along the channel. However, the incoming particles in subsequent surges would move along the deposit surface, suffering relatively high friction and rolling resistance at inter-particle collisions. The granular resistant effects would be dominant for dense granular flux, when the deposits pile up slowly. For comparisons, the deposit lengths of dry grains 
behave differently from the surged motion of grains in fluid. The forward and backward lengths of dry grains are the same throughout the simulation and the maximum normalized deposit length is 1.5 , which is very close to the backward deposit length of the third surge of granular deposits in water.

The evolution of sediment heights for both DEM-CFD coupling and dry granular simulations are illustrated in Figure 13. In these simulations, the deposit height is defined as the height of the static sediment layer during the simulation. According to Figure 13, it can be observed that the deposit height of the grains increases slowly with time, until the sediment layer reaches the river water table. For grains settling in water, the deposit height is much smaller than that of dry granular assembly during the simulations, and the corresponding time for reaching the maximum deposit height is longer than that of dry sediments. In addition, a series of constant height periods can also be observed for granular deposits in water (see the time periods of 5-7, 9-12 and 13-16), due to the transportation of particles to the surging front.

\subsubsection{Granular transport at different flow velocities}

The analyses discussed in previous sections only focus on a specific model configuration of solid grains settling into a static fluid channel and the corresponding comparisons with dry granular sedimentations. However, as discussed in Section 2.2, the rivers always flow at some specific velocities, which can significantly influence the transportation and depositional morphology of granular mass, regarding the deposit profile, evolution of deposit length and height. Thus, in the current study, a series of DEM-CFD coupled simulations have been performed, with the flow velocity varying from $0 \mathrm{~m} / \mathrm{s}$ to $10 \mathrm{~m} / \mathrm{s}$.

Figure 14 illustrates the granular profiles simulated by the DEM-CFD coupling model using different flow velocities. The fluid velocity fields were plotted as vectors on the same figures. It can be observed that the fluid velocities were disturbed significantly by the granular motions, while the solid grains tend to be transported towards the fluid outlet direction, as clearly shown on Figure 14(b) and (c). When compared with the results shown in Figure 7, the surged motion of grains still exist and the grains can spread along the bottom floor forming a wide deposit layer. For simulations using the flow velocity of $1 \mathrm{~m} / \mathrm{s}$, the evolution of deposit profile is almost the same as that shown in Figure 7. The only difference is that the grains are entrained in the flow stream and transported slightly forwards, as can be observed 
on the graph for $[\mathrm{T}]=2$. When the flow velocity is $10 \mathrm{~m} / \mathrm{s}$, all the grains can suspend in fluid and be transported long distances away from the source towards the flow outlet region. The maximum angles of repose measured on Figure 14 (a), (b) and (c) are $26^{\circ}, 39^{\circ}$ and $28^{\circ}$, respectively. During the simulations, the flow velocities within the static sediment piles were very small or even nil. Once the granular deposits reach the water table to form a dam, the fluid flow is completely blocked. As a consequence, the fluids behind the dam flows towards the dam peak, meaning an increase of water table would occur, while fluids in front of the dam flow downwards, indicating the water table would decrease gradually. The numerical results can reasonably describe the formation of landslide dams and the changes of water levels.

Quantitative analyses of deposit lengths and heights for simulations using various flow velocities are shown in Figure 15. According to Figure 15(a), it can be observed that for fluid flows with non-zero initial velocities, the forward deposit length is always larger than the backward deposit length. This phenomenon can be explained by the fact that the initial fluid flow together with the velocities induced by particle sedimentations into the fluid channel can entrain the particles to move forwards along the channel. The difference between the forward and backward deposit lengths is very large for grains transported by fluid at velocities of 5 $\mathrm{m} / \mathrm{s}$ and $10 \mathrm{~m} / \mathrm{s}$. For these cases, the incoming grains are transported forwards by the fast moving fluid streams, such that a large number of grains can move long distances away from the source region. For the case of $U=10 \mathrm{~m} / \mathrm{s}$, the normalized backward deposit length is zero, while the normalized forward deposit length can be as long as 9. This phenomenon indicates that when soil/rock mass falls into a fast moving river, the landslide dam can be formed at a long distance away from the slide source region. Figure 15(b) illustrates that the evolution of deposit heights follows almost the same trend for a series of simulations, and the constant height periods are evident to be observed. For $U=10 \mathrm{~m} / \mathrm{s}$, as the sediments initially pile up near the outlet region, the subsequent incoming particles would add mass to the deposits. The deposit height can only be changed when particles with large momentums move onto the deposit peak region. As a result, the deposit height changes as a series of constant height periods, as shown on Figure 15(b). 


\subsubsection{Particle-particle and particle-fluid interactions}

In this study, it is interesting to monitor the evolutions of the mean particle normal contact force $\left(F_{c}\right)$ and total particle-fluid interaction forces $\left(F_{p-f}\right)$. The significance of analyzing these two quantities relies on the fact that the inter-particle contact forces are dominant during the formation of granular piles, while the total particle-fluid interaction forces quantify the momentum and energy transferred from the particles to the fluids (Shan and Zhao 2014). In the current analyses, the mean normal contact forces and the particle-fluid interaction forces are normalized by the gravity of a single particle with its radius being $0.2 \mathrm{~m}$, as defined in Eq.(14).

Figure 16 illustrates the evolution of mean normal contact forces of the granular system. It can be observed that for granular particles transported by different flow velocities, the mean normal contact forces increases quickly to the peak value at almost the same time (around [T] $=2.5$ ), when they drop into the fluid channel and begin to collide with each other. The numerical results show that the peak mean normal contact forces increase with the flow velocity, as intensive particle collisions would occur in a highly disturbed granular system. However, for $U=0 \mathrm{~m} / \mathrm{s}$ and $U=1 \mathrm{~m} / \mathrm{s}$, the evolutions of the mean normal contact forces are very similar, with the same peak value of 75 , indicating that particles behave similarly in the fluid channel at low flow velocities. When compared with the dry case, the peak mean normal contact force can be reduced by $60 \%$ at the presence of water due to the fluid viscous drag effect. As the incoming particles would gradually pile up on the bottom floor, the gravities of particles dominate in the particle-particle interactions. As a consequence, the mean normal contact forces decrease quickly. It would reach a constant value of 9 after $[\mathrm{T}]=20$ for simulations using different flow velocities. As for the dry granular system, the peak mean normal contact force occurs at the beginning of the simulation when the particles collide with each other on the bottom at high velocities. It reaches a constant value of 20 after $[\mathrm{T}]=10$.

The evolution of total particle-fluid interaction forces are presented in Figure 17. It can be observed that the total particle-fluid interaction forces increase almost linearly with time, and the evolutions of $\left[F_{p-f}\right]$ are almost the same for different flow velocities. The numerical results indicate that the total particle-fluid interaction forces are independent of the fluid flow velocities. Since the particle-fluid interactions (especially the drag forces) are closely related to the relative velocities, the numerical results can also be interpreted as that on average, the 
same relative velocities between particle and fluid can be reached at any specific time. Even though the granular dynamics in fluid can be dramatically different for these cases (see Figure 14), the particle-fluid interactions might be dominated only by the constant granular flux into the fluid channel, as will be discussed in the following section. The linear fitting equation of these curves can be formulated as:

$$
\left[F_{p-f}\right]=1740+261 \times[T]
$$

\subsubsection{Granular transport at different granular fluxes}

The previous analyses have focused on exploring the mechanism of the formation of landslide dams at various flow velocities, while the granular flux $\left(Q_{p}\right)$ into the fluid channel was kept constant. Actually, the granular flux could possibly influence the fluid flow behaviour, which would in turn affect the particle transportation and deposition in the fluid channel. Thus, it is necessary to investigate the influence of granular flux on the granular dynamics in the fluid channel, as reported in this section. For all numerical results presented in this section, the fluid flow velocity is set as $5 \mathrm{~m} / \mathrm{s}$ in the corresponding simulations.

Figure 18 presents the final shapes of granular piles when the fluid channel is blocked for simulations. It can be observed that the granular piles have very similar shapes for simulations using various granular fluxes, indicating that the value of $Q_{p}$ has little influence on the depositional behaviour of the granular system. Quantitative analyses of the evolutions of sediments lengths and heights are illustrated in Figure 19. As shown in Figure 19(a), the forward lengths of sediments in different simulations increase linearly with time, until the constant forward lengths are reached. The increasing rate of the sediments lengths increases with the granular flux, indicating that the granular mobility in fluids is enhanced by the high granular flux into the channel. In addition, the particles start to move backwards at an early time if the granular flux is large. The evolution curves of backward lengths have very similar shapes for these three simulations. Figure 19(b) illustrates the evolution of sediments heights over time. It is evident to observe that the time required by the granular pile to block the river is inversely related to $Q_{p}$, as expected.

Figure 20(a) shows that the evolutions of mean normal contact forces of the granular system using different values of $Q_{p}$ are very similar, indicating that the granular dynamics in 
fluids are not significantly affected by the granular flux. The constant mean normal contact forces occur after $[\mathrm{T}]=15$, when the stable granular assemblies pile up on the floor. Due to the difference of granular weight, the value of constant $\left[F_{c}\right]$ increases slightly with the value of $Q_{p}$. Figure 20(b) shows that the total particle-fluid interaction forces increase almost linearly with time. At any specific time, the value of $\left[F_{p-f}\right]$ increases with the granular flux, indicating that an increasing amount of momentum and energy will be transferred from granular system to fluids.

According to the above discussions, the granular flux into the fluid channel has very little influence on the depositional pattern of granular sediments, while it can affect the particlefluid interactions significantly. Since this study only focus on the formation of landslide dams, the granular flux $\left(Q_{p}=640 / \mathrm{s}\right)$ used in this study is reasonable for analyzing the granular transportation and deposition in fluid channels.

\section{Conclusions}

This paper presents numerical investigations of the formation of landslide dams via the coupled DEM-CFD simulations. By analysing the behaviour of granular transportation and deposition in a fluid channel, the influence of fluid flow on the depositional morphology has been clarified. The main concluding points are summarized as below:

(1) The sedimentation of grains can generate excess water pressures at the bottom, which helps to reduce the effective stresses of the granular mass. In the meantime, the fluid flow is disturbed by the grain motion, triggering the fluid stream to flow backwards and forwards. The coupled effects of excess water pressure and fluid flow can entrain the suspended grains to move long distances. In the whole process of granular transportation and deposition, the granular flows experience the transition from loose to dense regimes.

(2) The final deposit of submerged deposits have a relatively flat profile, with much larger deposit lengths than that obtained in simulations using dry granular materials. For grains settled in the fluid channel, the larger flow velocity is, the longer time it is required to form landslide dams in the river.

(3) The locations of the deposited grains are closely related to the flow velocity. The larger the flow velocity is, the longer distance the grains can be transported to. Thus, 
in rivers with very fast flows, the landslide dams may be formed some distance away from the slide source region.

(4) The peak mean normal contact force of the granular system can be reduced by $60 \%$ at the presence of water. For simulations using different flow velocities, the final constant mean normal contact forces are the same, as determined by the gravity of particles. In addition, the evolutions of particle-fluid interaction forces are almost the same for simulations under study, with the total particle-fluid interaction forces increasing linearly with time.

(5) The granular flux into the fluid channel has very little influence on the depositional pattern of particles, while it affects the particle-fluid interactions significantly.

The current research on landslide dams only focus on the very short time period of granular dynamics in water. The results obtained in this paper can reasonably explain the complex fluid-solid interactions occurred in the process of granular transportation and sedimentation. Further research on this topic will be comprehensive analyses of the whole process of landslide formation, including the failure of slope mass, granular motion in water, the generation of impulse waves, and the subsequent breaching of landslide dams.

\section{$5 \quad$ Acknowledgements}

This work is supported by the research grants from National Program on Key basic Research Project (No. 2015CB057903), Program for New Century Excellent Talents in University (NCET-13-0382), the Youth Science and Technology Fund of Sichuan Province (2014JQ0004), and the 'Program of Young scholars from Renowned Universities or Institutes' at Sichuan University, China,

\section{$6 \quad$ References}

Abe S, Place D and Mora P (2004) A parallel implementation of the lattice solid model for the simulation of rock mechanics and earthquake dynamics. Pure Appl Geophys 161: 2265-2277. doi: $10.1007 / \mathrm{s} 00024-004-2562-\mathrm{x}$ 
Anderson JD (1995) Computational fluid dynamics: The basics with applications. McGraw-Hill,

Belheine N, Plassiard JP, Donzé FV, Darve F and Seridi A (2009) Numerical simulation of drained triaxial test using 3d discrete element modeling. Comput Geotech 36: 320-331.

Brown P and Lawler D (2003) Sphere drag and settling velocity revisited. J Environ Eng 129: 222-231. doi: 10.1061/(asce)0733-9372(2003)129:3(222)

Casagli N, Ermini L and Rosati G (2003) Determining grain size distribution of the material composing landslide dams in the northern apennines: Sampling and processing methods. Eng Geol 69: 83-97. doi: 10.1016/s0013-7952(02)00249-1

Cassar C, Nicolas M and Pouliquen O (2005) Submarine granular flows down inclined planes. Physics of Fluids 17. doi: Doi 10.1063/1.2069864

Chang DS and Zhang LM (2010) Simulation of the erosion process of landslide dams due to overtopping considering variations in soil erodibility along depth. NHESS 10: 933-946.

Chen F, Drumm EC and Guiochon G (2011) Coupled discrete element and finite volume solution of two classical soil mechanics problems. Comput Geotech 38: 638-647. doi: 10.1016/j.compgeo.2011.03.009

Crosta GB, Frattini P and Fusi N (2007) Fragmentation in the val pola rock avalanche, italian alps. Journal of Geophysical Research: Earth Surface 112: F01006. doi: 10.1029/2005jf000455

Cundall PA and Strack ODL (1979) A discrete numerical model for granular assemblies. Géotechnique 29: 47-65.

Di Felice R (1994) The voidage function for fluid-particle interaction systems. Int J Multiphas Flow 20: $153-159$.

Duman TY (2009) The largest landslide dam in turkey: Tortum landslide. Engineering Geology 104: 66-79. doi: http://dx.doi.org/10.1016/j.enggeo.2008.08.006

Fan X, Tang CX, Van Westen CJ and Alkema D (2012) Simulating dam-breach flood scenarios of the tangjiashan landslide dam induced by the wenchuan earthquake. Nat Hazards Earth Syst Sci 12: 3031-3044.

Fan X, van Westen CJ, Xu Q, Gorum T and Dai F (2012) Analysis of landslide dams induced by the 2008 wenchuan earthquake. Journal of Asian Earth Sciences 57: 25-37. doi: http://dx.doi.org/10.1016/j.jseaes.2012.06.002

Gue CS (2012) Submarine landslide flows simulation through centrifuge modelling - phd thesis. University of Cambridge

Huang X and Tang C (2014) Formation and activation of catastrophic debris flows in baishui river basin, sichuan province, china. Landslides 11: 955-967. doi: 10.1007/s10346-014-0465-1

Ischuk AR (2011) Usoi rockslide dam and lake sarez, pamir mountains, tajikistan. In: Evans SG, Hermanns RL, Strom A and Scarascia-Mugnozza G (eds) Natural and artificial rockslide dams, Springer Berlin Heidelberg, pp 423-440

Jiang MJ, Yu HS and Harris D (2005) A novel discrete model for granular material incorporating rolling resistance. Comput Geotech 32: 340-357. doi: 10.1016/j.compgeo.2005.05.001

Kafui KD, Thornton C and Adams MJ (2002) Discrete particle-continuum fluid modelling of gassolid fluidised beds. ChEnS 57: 2395-2410.

Launder BE and Spalding DB (1972) Mathematical models of turbulence. Academic Press,

Li J, Webb C, Pandiella SS, Campbell GM, Dyakowski T, Cowell A and McGlinchey D (2005) Solids deposition in low-velocity slug flow pneumatic conveying. Chem Eng Process 44: 167-173. doi: 10.1016/j.cep.2004.02.011 
Liu N, Zhang J, Lin W, Cheng W and Chen Z (2009) Draining tangjiashan barrier lake after wenchuan earthquake and the flood propagation after the dam break. Science in China Series E: Technological Sciences 52: 801-809. doi: 10.1007/s11431-009-0118-0

Micu M and Bălteanu D (2013) A deep-seated landslide dam in the siriu reservoir (curvature carpathians, romania). Landslides 10: 323-329. doi: 10.1007/s10346-013-0382-8

Micu M, Jurchescu M, Micu D, Zarea R, Zumpano V and Bălteanu D (2014) A morphogenetic insight into a multi-hazard analysis: Bâsca mare landslide dam. Landslides 11: 1131-1139. doi: 10.1007/s10346-014-0519-4

Nakamura $\mathrm{H}$, Iwasaki $\mathrm{T}$ and Watano S (2006) Numerical simulation of film coating process in a novel rotating fluidized bed. Chem Pharm Bull 54: 839-846. doi: Doi 10.1248/Cpb.54.839

OpenCFD (2014) Openfoam - the open source cfd toolbox, http://www.Openfoam.Com/.

Shan T and Zhao JD (2014) A coupled cfd-dem analysis of granular flow impacting on a water reservoir. AcMec 225: 2449-2470. doi: 10.1007/s00707-014-1119-z

Topin V, Monerie Y, Perales F and Radjai F (2012) Collapse dynamics and runout of dense granular materials in a fluid. Phys Rev Lett 109.

Utili S, Zhao T and Houlsby GT (2015) 3d dem investigation of granular column collapse: Evaluation of debris motion and its destructive power. Eng Geol 186: 3-16. doi: http://dx.doi.org/10.1016/j.enggeo.2014.08.018

Wang B, Xu DL, Chu KW and Yu AB (2006) Numerical study of gas-solid flow in a cyclone separator. Appl Math Model 30: 1326-1342. doi: 10.1016/j.apm.2006.03.011

Wang G and Sassa K (2001) Factors affecting rainfall-induced flowslides in laboratory flume tests. Geotechnique 51: 587-599.

Wilcox DC (2006) Turbulence modeling for cfd. DCW Industries, Incorporated,

Wu C-H, Chen S-C and Feng Z-Y (2014) Formation, failure, and consequences of the xiaolin landslide dam, triggered by extreme rainfall from typhoon morakot, taiwan. Landslides 11: 357-367. doi: 10.1007/s10346-013-0394-4

Xu BH, Yu AB, Chew SJ and Zulli P (2000) Numerical simulation of the gas-solid flow in a bed with lateral gas blasting. Powder Technol 109: 13-26. doi: Doi 10.1016/S0032-5910(99)00223-5

Xu Q, Fan X-M, Huang R-Q and Westen C (2009) Landslide dams triggered by the wenchuan earthquake, sichuan province, south west china. Bulletin of Engineering Geology and the Environment 68: 373-386. doi: 10.1007/s10064-009-0214-1

Xu W-J, Xu Q and Wang Y-J (2013) The mechanism of high-speed motion and damming of the tangjiashan landslide. Eng Geol 157: 8-20. doi: http://dx.doi.org/10.1016/j.enggeo.2013.01.020

Yan J, Cao Z-x, Liu H-h and Chen L (2009) Experimental study of landslide dam-break flood over erodible bed in open channels. Journal of Hydrodynamics, Ser B 21: 124-130. doi: http://dx.doi.org/10.1016/S1001-6058(08)60127-4

Zhao J and Shan T (2013) Coupled cfd-dem simulation of fluid-particle interaction in geomechanics. Powder Technol 239: 248-258. doi: http://dx.doi.org/10.1016/j.powtec.2013.02.003

Zhao T, Houlsby GT and Utili S (2014) Investigation of granular batch sedimentation via dem-cfd coupling. Granul Matter 16: 921-932. doi: 10.1007/s 10035-014-0534-0

Zhao T, Utili S and Crosta GB (2015) Rockslide and impulse wave modelling in the vajont reservoir by dem-cfd analyses. Rock Mech Rock Eng: 1-20. doi: 10.1007/s00603-015-0731-0

Zhou GD, Cui P, Chen HY, Zhu XH, Tang JB and Sun QC (2013) Experimental study on cascading landslide dam failures by upstream flows. Landslides 10: 633-643. doi: 10.1007/s10346-012-0352-6 
Zhou J-w, Cui P and Fang H (2013) Dynamic process analysis for the formation of yangjiagou landslide-dammed lake triggered by the wenchuan earthquake, china. Landslides 10: 331-342. doi: 10.1007/s10346-013-0387-3

Zhu HP, Zhou ZY, Yang RY and Yu AB (2008) Discrete particle simulation of particulate systems: A review of major applications and findings. ChEnS 63: 5728-5770. 
Table 1. Input parameters for the simulations presented herein.

Table 2. Input parameters of the grain settling model

Figure 1. Schematic view of a slope mass sliding into a river

Figure 2. Schematic view of the granular transport model

Figure 3. Particle size distribution curves of the Tangjiashan landslide dam (Chang and Zhang 2010) and the DEM model

Figure 4. Non-slip boundary of fluid flow in the CFD turbulent model

Figure 5. Transportation velocity of a single particle

Figure 6. Settling velocity of a single particle

Figure 7. Evolution of the deposit profiles. The first surge is enclosed by red dashed curves; the second surge is enclosed by yellow dashed curves; the third surge is enclosed by pink dashed curves.

Figure 8. Evolution of dry granular deposit profile

Figure 9. Evolution of excess water pressure in the fluid channel (the black curves represent the granular profile)

Figure 10. Variation of excess water pressure of the region below the grain container near the channel floor

Figure 11. Evolution of flow velocity fields (the black curves represent the granular profile)

Figure 12. Evolution of the sediment lengths ("S1", "S2" and "S3" represents the first, second and third granular surges of the sediments flow; "dry" represents the dry granular deposit.)

Figure 13. Evolution of the sediment heights

Figure 14. Evolution of the deposit profiles and fluid velocity fields for fluid flow at velocity (a) $1 \mathrm{~m} / \mathrm{s}$, (b) $5 \mathrm{~m} / \mathrm{s}$, (c) $10 \mathrm{~m} / \mathrm{s}$

Figure 15. Evolution of sediment (a) length and (b) height for varies flow conditions

Figure 16. Evolution of mean normal contact forces in the granular system

Figure 17. Evolution of total interaction forces between the fluid and the granular system

Figure 18. Granular depositions for different granular flux: (a) $\mathrm{Q}_{\mathrm{p}}=640 / \mathrm{s}$, (b) $\mathrm{Q}_{\mathrm{p}}=425 / \mathrm{s}$; (c) $\mathrm{Q}_{\mathrm{p}}=$ $320 / \mathrm{s}$

Figure 19. Evolution of sediment (a) length and (b) height for various granular flux

Figure 20. Evolution of (a) mean normal contact force and (b) total particle-fluid interaction forces 


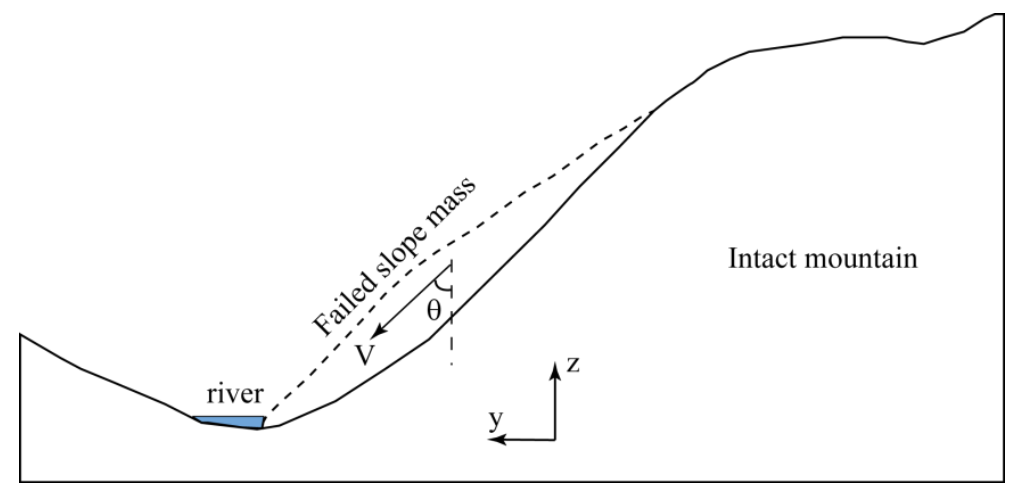

Figure 1. Schematic view of a slope mass sliding into a river

3

4
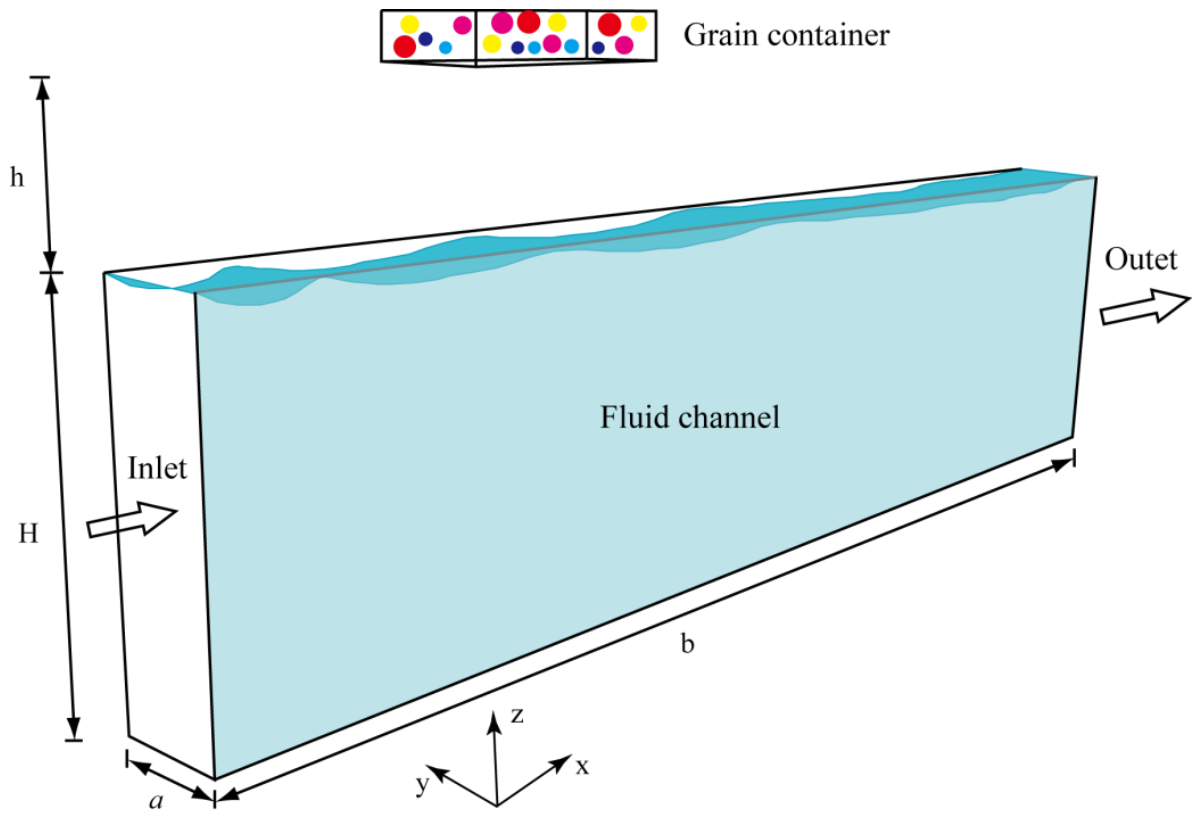

Figure 2. Schematic view of the granular transport model 


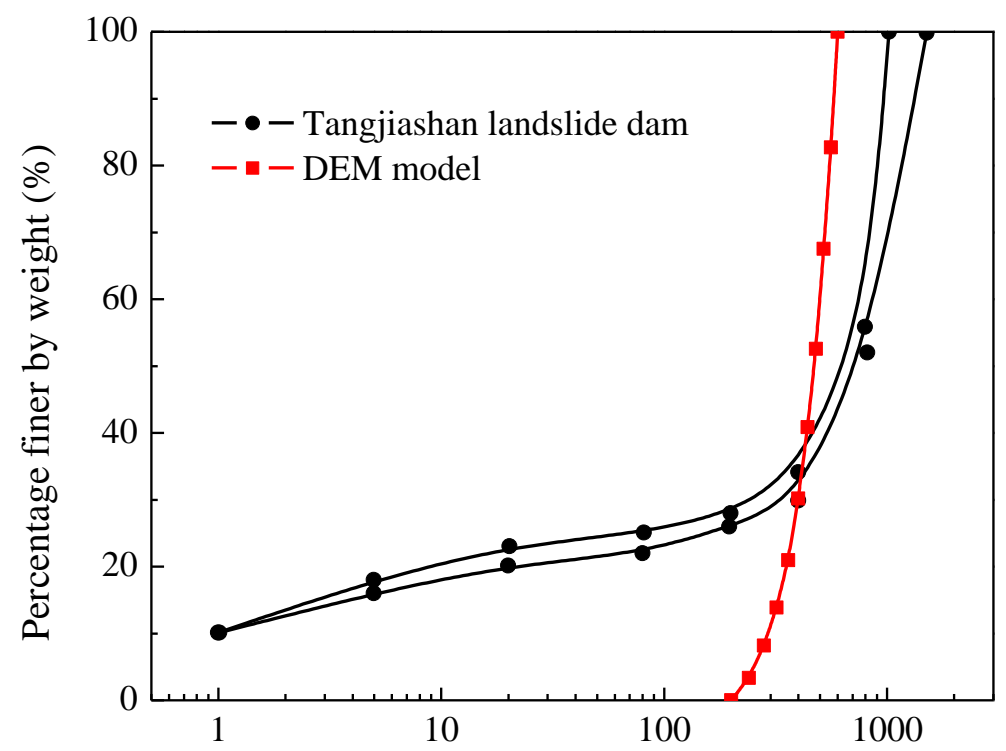

Particle size (mm)

Figure 3. Particle size distribution curves of the Tangjiashan landslide dam (Chang and Zhang 2010) and the DEM model

10

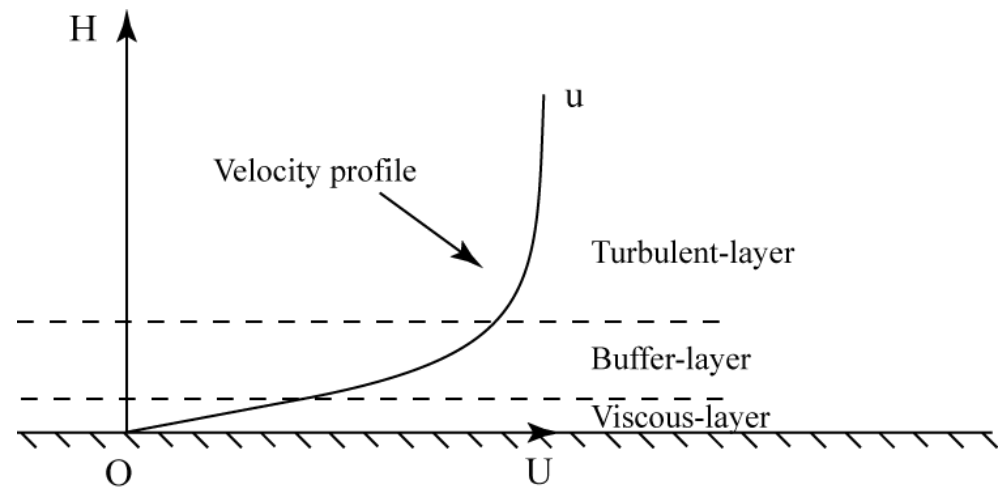

Figure 4. Non-slip boundary of fluid flow in the CFD turbulent model 


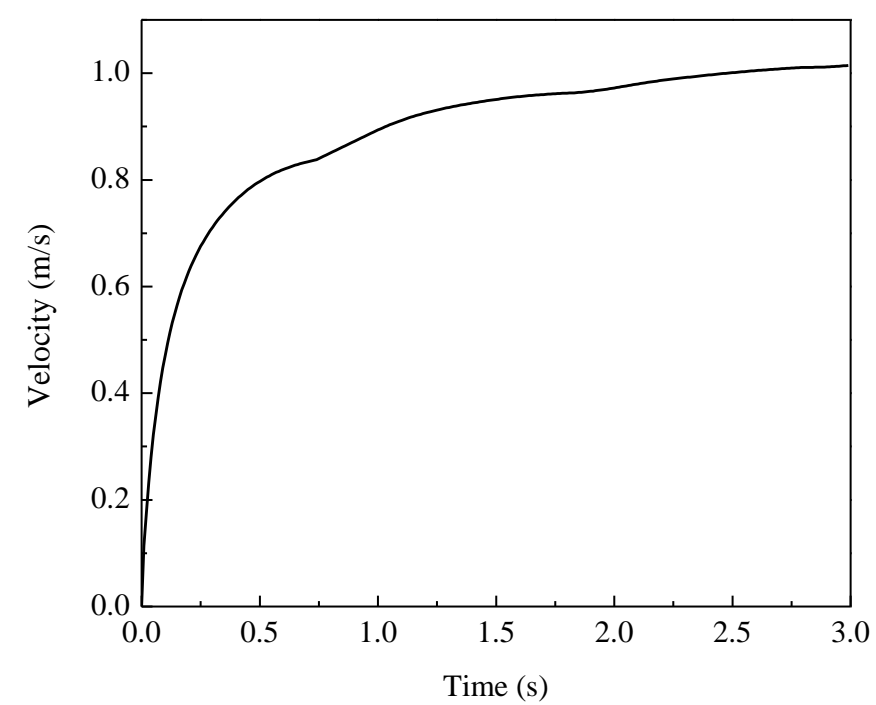

Figure 5. Transportation velocity of a single particle

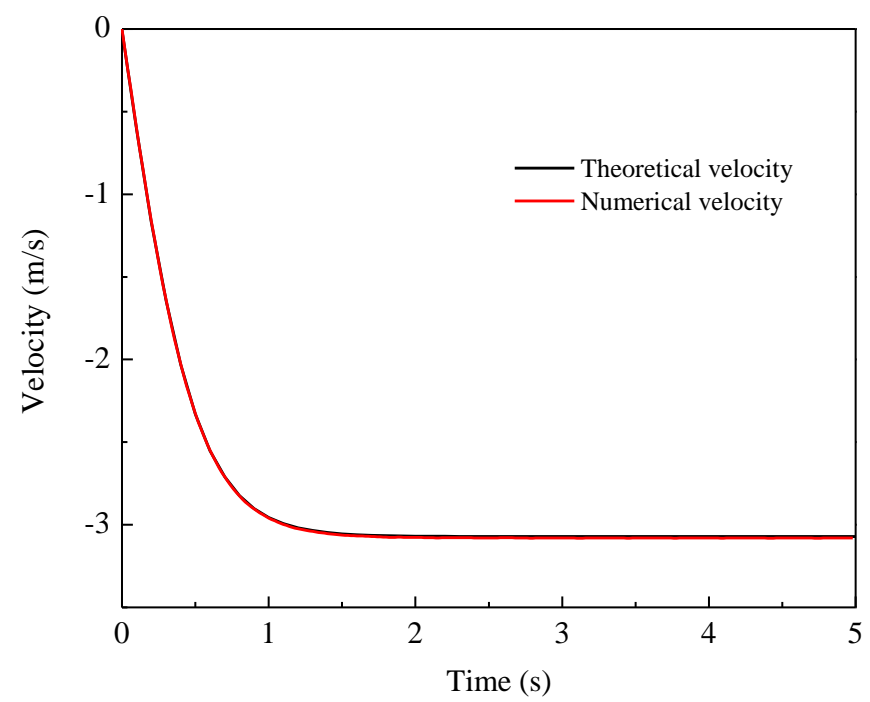

19

Figure 6. Settling velocity of a single particle
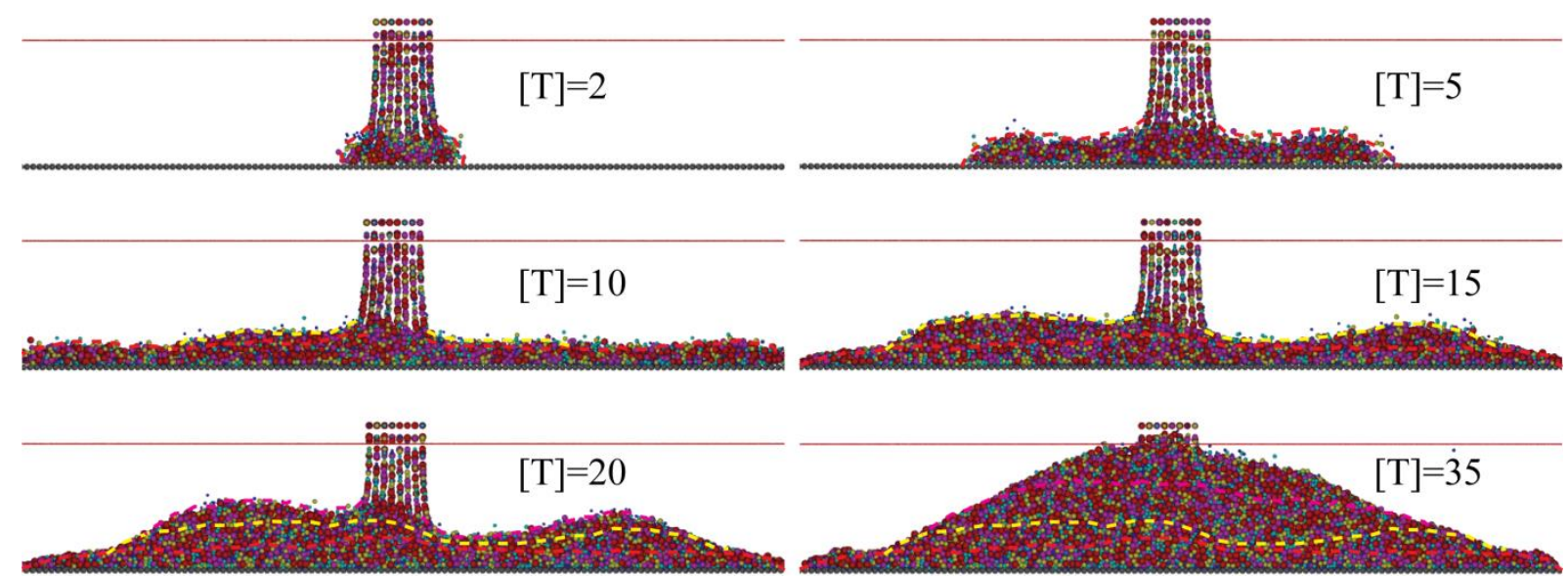

Figure 7. Evolution of the deposit profiles. The first surge is enclosed by red dashed curves; the second surge is enclosed by yellow dashed curves; the third surge is enclosed by pink dashed curves. 

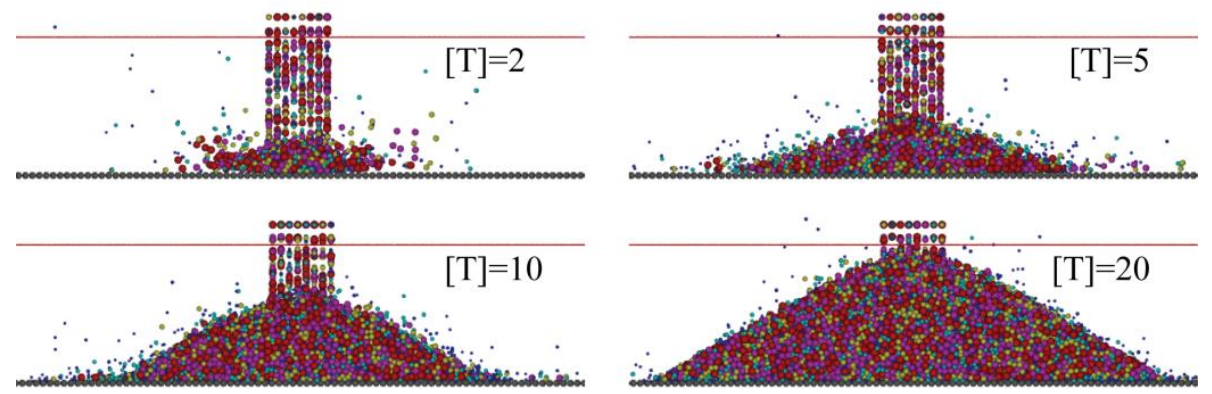

Figure 8. Evolution of dry granular deposit profile
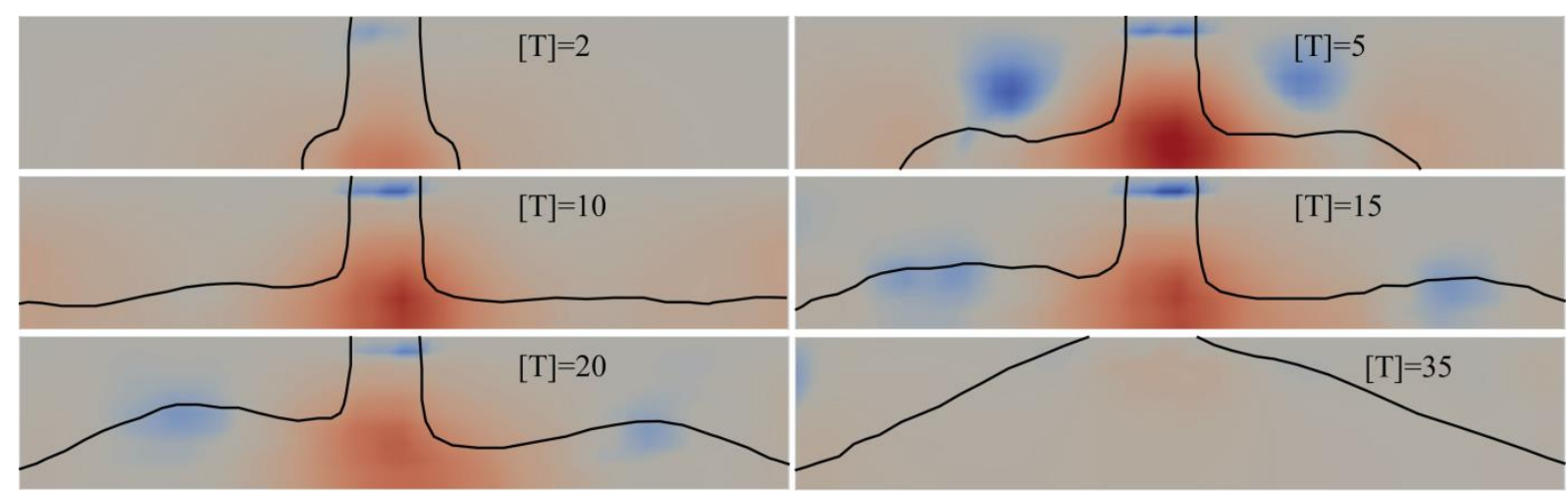

$-0.1$

0

0.1

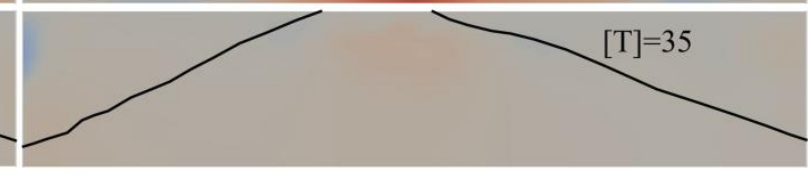

[p]

$\begin{array}{llll}0.2 & 0.3 & 0.4 & 0.5\end{array}$

Figure 9. Evolution of excess water pressure in the fluid channel (the black curves represent the granular profile)

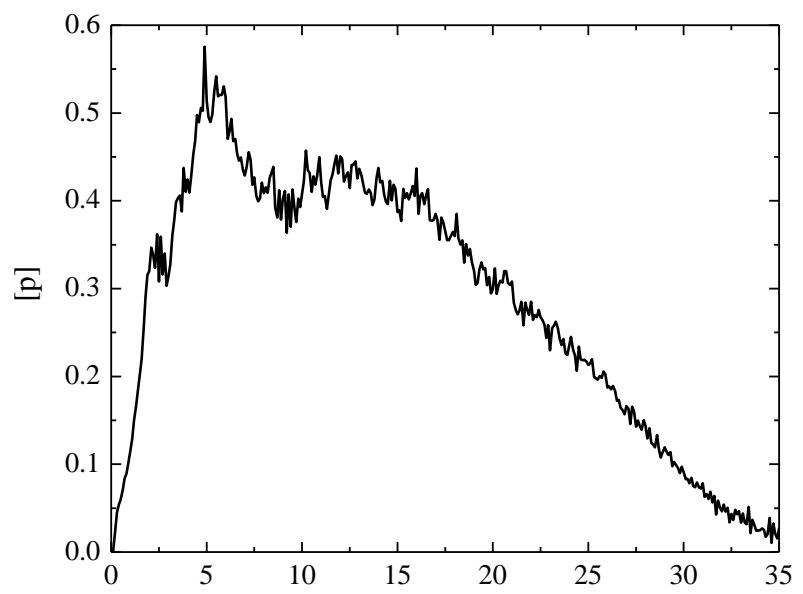

[T]

Figure 10. Variation of excess water pressure of the region below the grain container near the channel floor 


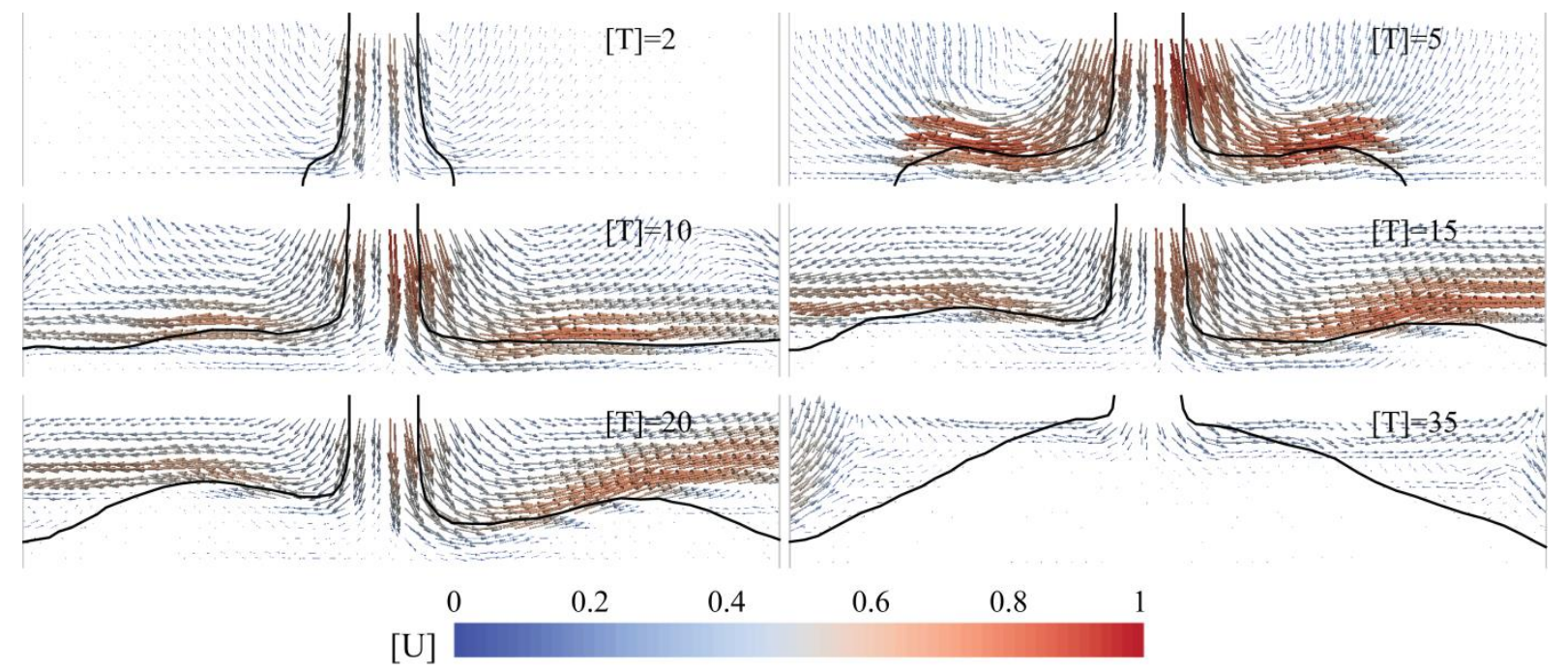

Figure 11. Evolution of flow velocity fields (the black curves represent the granular profile)

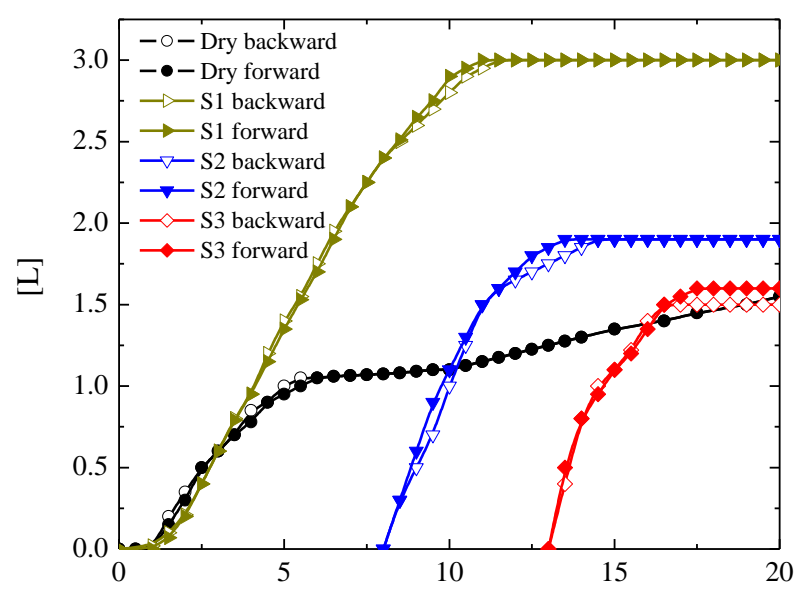

36

Figure 12. Evolution of the sediment lengths ("S1", "S2" and "S3" represents the first, second and third granular surges of the sediments flow; "dry" represents the dry granular deposit.)

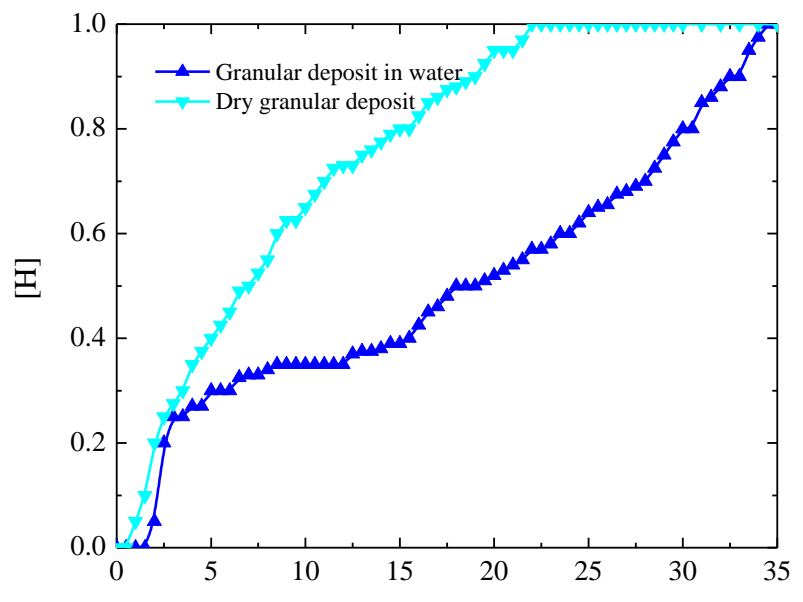

$[\mathrm{T}]$

Figure 13. Evolution of the sediment heights 
(a)
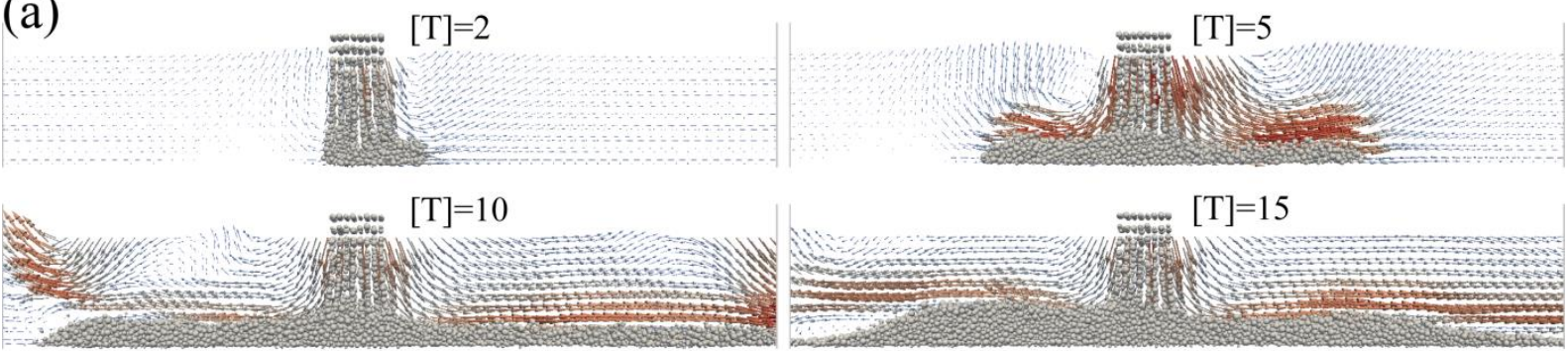

41
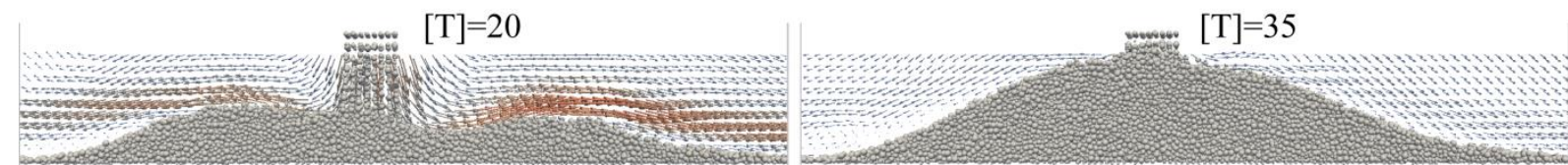

(b)

$[\mathrm{T}]=2$
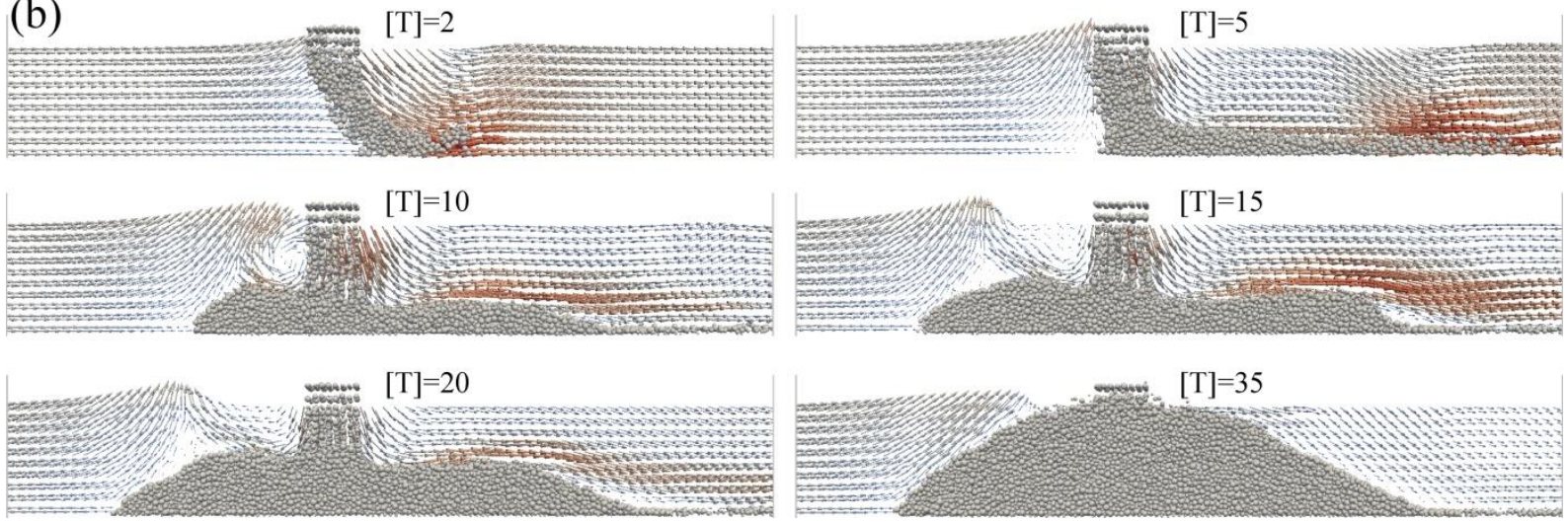

(c)

$[\mathrm{T}]=2$
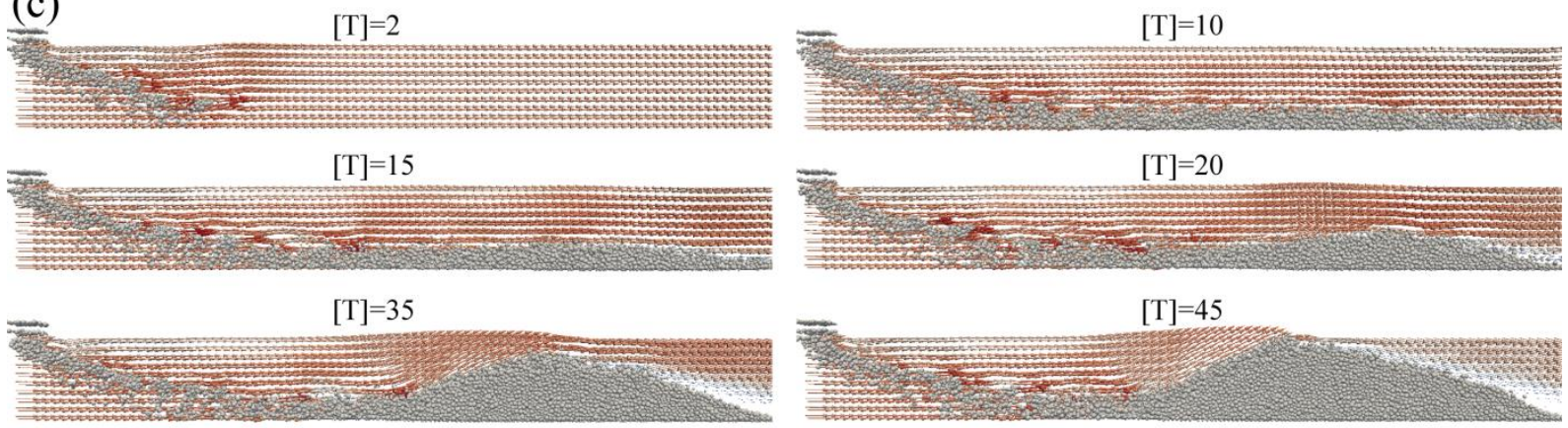

Figure 14. Evolution of the deposit profiles and fluid velocity fields for fluid flow at velocity (a) $1 \mathrm{~m} / \mathrm{s}$, (b) $5 \mathrm{~m} / \mathrm{s}$, (c) $10 \mathrm{~m} / \mathrm{s}$ 

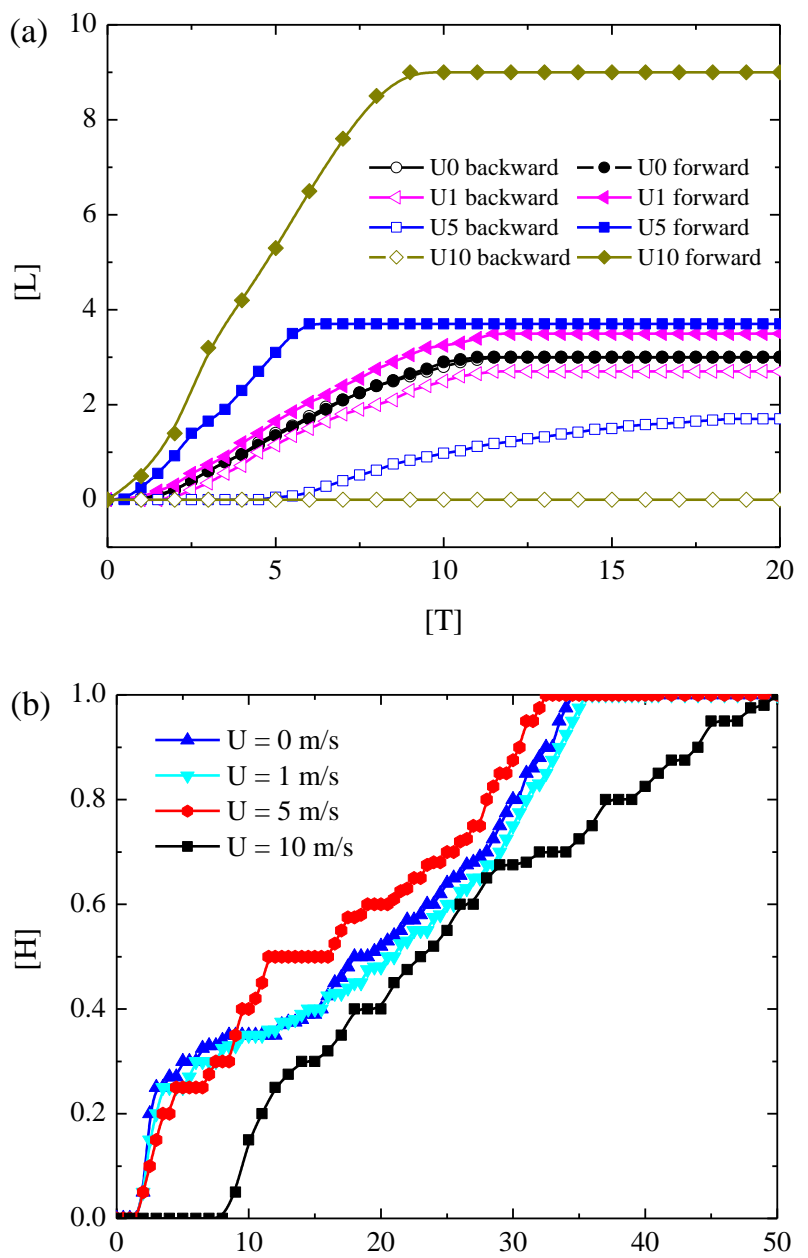

[T]

Figure 15. Evolution of sediment (a) length and (b) height for varies flow conditions

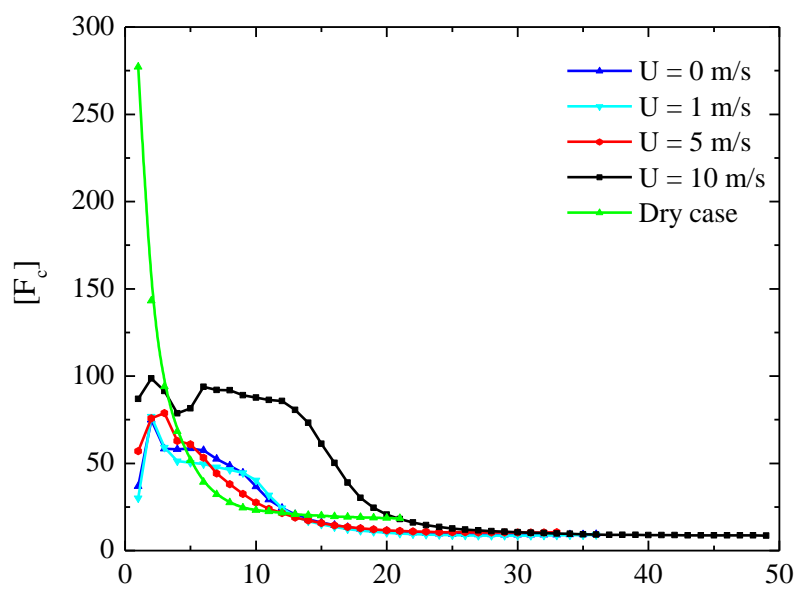

Figure 16. Evolution of mean normal contact forces in the granular system 


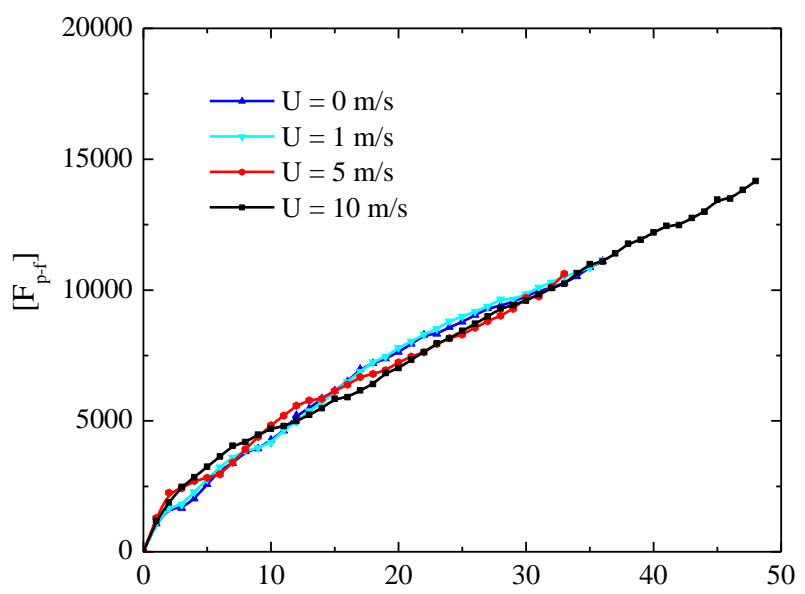

61

(a)

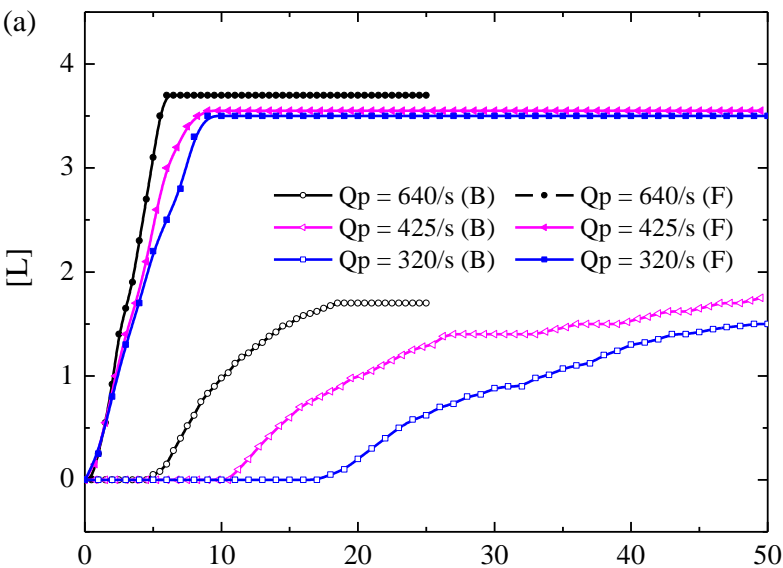

[T]

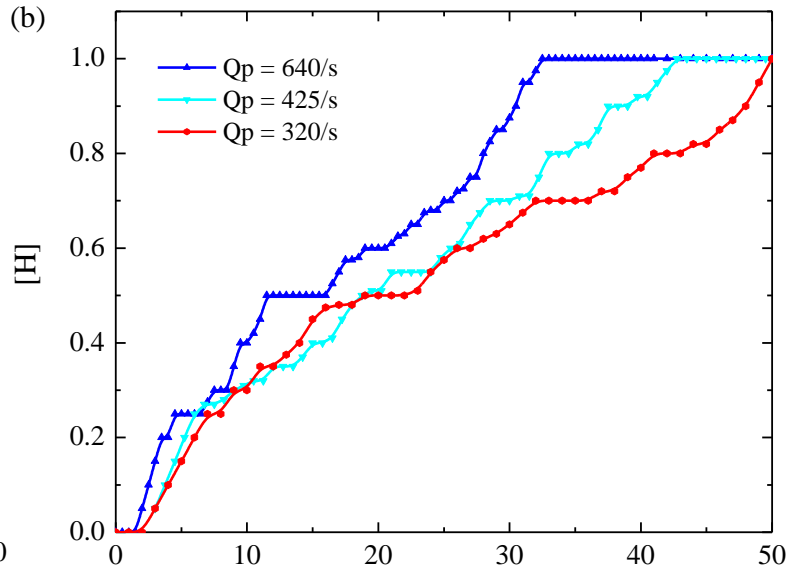

[T]

Figure 19. Evolution of sediment (a) length and (b) height for various granular flux 


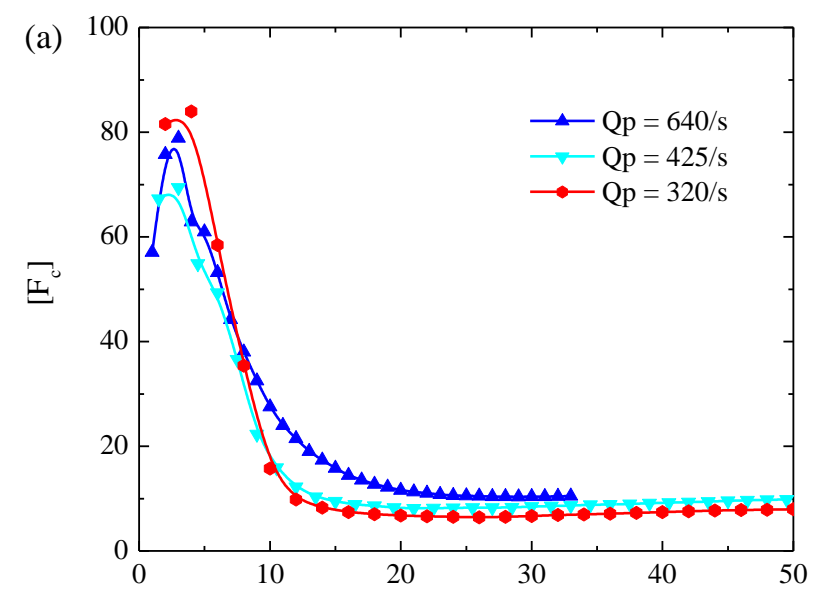

64

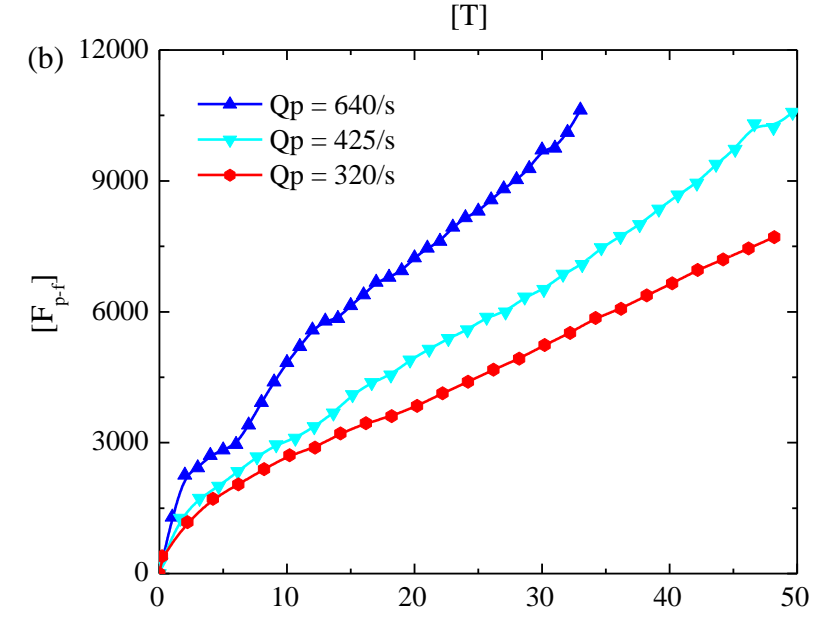

65

$[\mathrm{T}]$

Figure 20. Evolution of (a) mean normal contact force and (b) total particle-fluid interaction 67 forces 
Table 1. Input parameters for the simulations presented herein.

\begin{tabular}{|c|c|c|c|}
\hline DEM Parameters & Values & CFD Parameters & Values \\
\hline Particle radius, $r(\mathrm{~m})$ & {$[0.1,0.3]$} & Fluid density, $\rho_{f}\left(\mathrm{~kg} / \mathrm{m}^{3}\right)$ & 1000 \\
\hline Granular density, $\rho_{s}\left(\mathrm{~kg} / \mathrm{m}^{3}\right)$ & 2650 & Fluid viscosity, $\mu(\mathrm{Pa} \cdot \mathrm{s})$ & 0.001 \\
\hline Normal stiffness, $K_{n}(\mathrm{~N} / \mathrm{m})$ & $3.0 \times 10^{7}$ & Flow velocity, $U(\mathrm{~m} / \mathrm{s})$ & {$[0,10]$} \\
\hline Shear stiffness, $K_{s}(\mathrm{~N} / \mathrm{m})$ & $2.7 \times 10^{7}$ & CFD Time step size, $\Delta t_{f}(\mathrm{~s})$ & $10^{-4}$ \\
\hline Inter-particle friction angle, $\left(^{\circ}\right)$ & 30 & Coupling frequency $^{*}$ & 10 \\
\hline Coefficient of rolling stiffness, $\beta$ & 1.0 & & \\
\hline Coefficient of plastic moment, $\eta$ & 0.1 & & \\
\hline DEM Time step size, $\Delta t_{s}(\mathrm{~s})$ & $10^{-5}$ & & \\
\hline Gravity, $g\left(\mathrm{~m} / \mathrm{s}^{2}\right)$ & -9.81 & & \\
\hline
\end{tabular}

$2 *$ The coupling frequency is the iteration steps used in the DEM within one coupling interval.

3

4

Table 2. Input parameters of the grain settling model

\begin{tabular}{|c|c|c|c|}
\hline DEM Parameters & Values & CFD Parameters & Values \\
\hline Particle radius, $r(\mathrm{~m})$ & 0.1 & Fluid density, $\rho_{f}\left(\mathrm{~kg} / \mathrm{m}^{3}\right)$ & 1000 \\
\hline Granular density, $\rho_{s}\left(\mathrm{~kg} / \mathrm{m}^{3}\right)$ & 1000 & Viscosity, $\mu(\mathrm{Pa} \cdot \mathrm{s})$ & 0.001 \\
\hline Initial velocity, $V(\mathrm{~m} / \mathrm{s})$ & 0 & Initial velocity, $U(\mathrm{~m} / \mathrm{s})$ & 1 \\
\hline
\end{tabular}

5 